\title{
72 Die Immunologie des Überlastungssyndroms
}

\author{
(c) Springer-Verlag GmbH Deutschland, ein Teil von Springer Nature 2018 \\ D. Mathias, Fit und gesund von 1 bis Hundert \\ https://doi.org/10.1007/978-3-662-56307-6_72
}

Vom Überlastungssyndrom sind üblicherweise meist unerfahrene Sporttreibende mit einem hohen Ehrgeizpotenzial betroffen. Zunächst fällt den Betroffenen ihre rapide nachlassende körperliche Leistungsfähigkeit auf. Dann folgen gesundheitliche Beeinträchtigungen, die erhebliche Ausmaße annehmen können.

Wie jede körperliche Belastung beginnt das Übertrainingssyndrom (ÜTS) mit einer von den Interleukinen 1 und $\mathbf{6}$ sowie dem Tumornekrosefaktor a vermittelten Entzündungsreaktion zur Reparatur von Mikrorupturen in Muskulatur und Bindegewebe. Diese Botenstoffe werden als Myokine auch von der Muskulatur gebildet ( $\triangleright$ Kap. 54).
Bei andauernden körperlichen Überlastungen geht der eigentlich lokale Prozess allmählich in einen systemischen über. Dabei macht Interleukin 1 im limbischen System müde und gelegentlich Depressionen. Beide oben genannten Interleukine bewirken in den Gonaden Hormonsenkungen mit der Folge von Zyklusstörungen und Libidoverlust. Ferner veranlassen sie die Nebennieren zu einer gesteigerten Cortisolbildung. Cortisol fördert die Glucosebildung aus Glutamin, diese Aminosäure fehlt dann für spezielle Funktionen im Immunsystem. Außerdem hemmt Cortisol Interleukin 2 und beeinflusst dadurch negativ die zelluläre Immunabwehr.

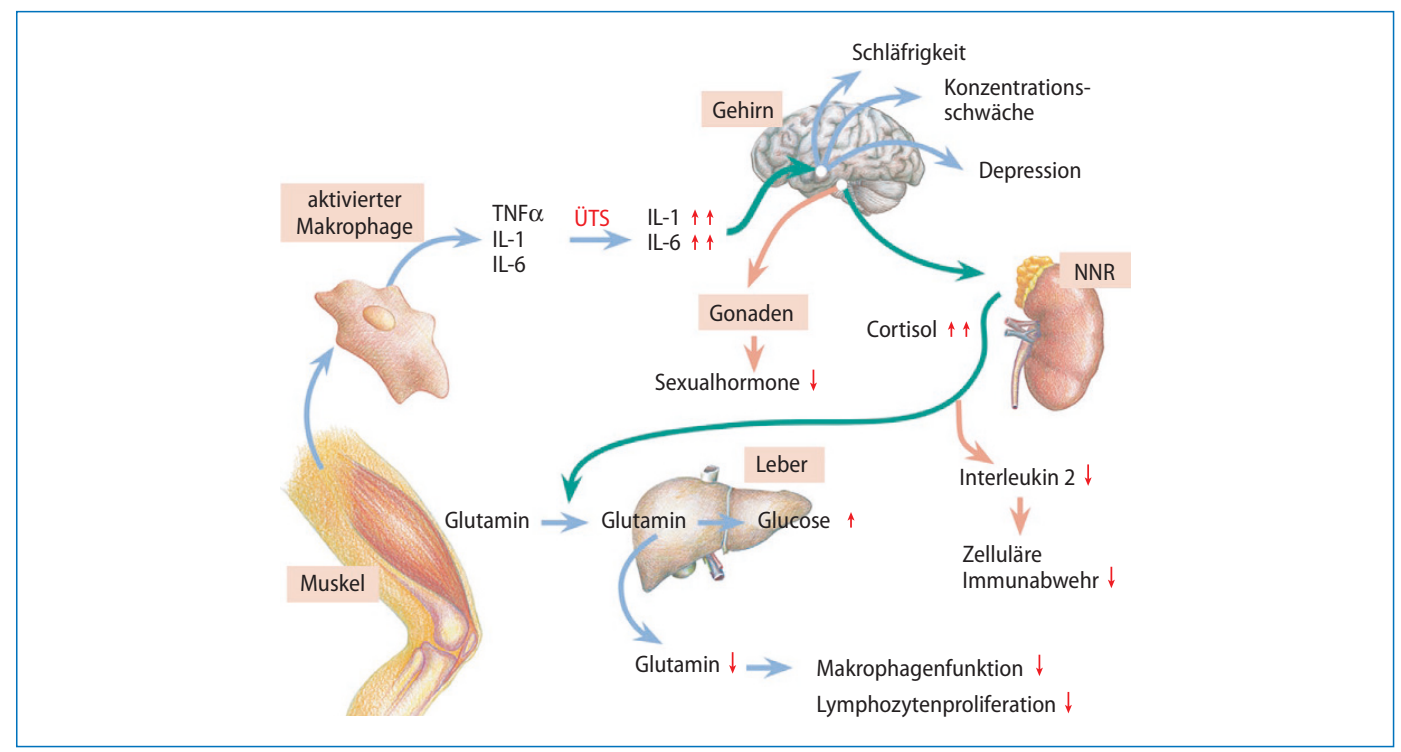

- Abb. 72.1 Biochemische Prozesse bei Überlastung; $\uparrow$ Erhöhung, $\downarrow$ Verminderung, ÜTS Übertrainigssyndrom, NNR Nebennierenrinde 